\title{
Pregnancy Located below the Internal Os - Cervical and Caesarean Scar Ectopics
}

\author{
Sumia Bari ${ }^{1}$, Gulshan $\mathrm{Ara}^{2}$, Kamrun Nessa ${ }^{3}$ \\ Received: January 5, 2015 Accepted: April 6, 2015 \\ doi: http://dx.doi.org/10.3329/jemc.v5i2.23386
}

\begin{abstract}
Cervical pregnancy is an extremely rare condition with potential grave consequences if not diagnosed early and treated properly. Here we report two cases of early cervical ectopic pregnancy with a history of previous one caesarean section. One case severely bled during evacuation and curettage and was successfully treated by hysterotomy followed by digital separation of product of conception. Another case was managed conservatively by medical method with injectable methotrexate.
\end{abstract}

J Enam Med Col 2015; 5(2): 118-121

\section{Introduction}

Cervical pregnancy is defined as the implantation of the conceptus within the cervix below the level of internal os. Caesarean scar pregnancy is a novel entity, which refers to a pregnancy implanted into a deficient uterine scar following previous lower segment caesarean section. ${ }^{1}$ Cervical ectopic pregnancy is extremely rare, accounting for less than $1 \%$ of all ectopic pregnancies. ${ }^{2}$ Its aetiology is still unclear. However, there are reports of association with chromosomal abnormalities as well as a prior history of procedures that damage the endometrial lining such as caesarean section, intrauterine device and in vitro fertilization. ${ }^{3}$ Prior to the introduction of high resolution transvaginal scanning, the distinction between cervical and caesarean scar pregnancies was not possible. In older literature, 33\% of "cervical" pregnancies occurred in women with a history of previous caesarean section, which indicates that scar pregnancies probably account for a significant number of ectopics below the level of internal os. ${ }^{4}$ Common characteristics of both cervical and caesarean scar pregnancies are implantation of conceptus into myometrial defects following previous

intrauterine surgery. In case of cervical pregnancy the implantation is usually into the false passage which occurred during previous attempts at cervical dilatation. As a result of myometrial involvement surgical evacuation of cervical or caesarean ectopics often results in serious haemorrhage. The bleeding tends to be more severe with increasing gestation. Pregnancies below the level of internal os are often viable and it is not unusual for caesarean ectopics to progress to full term. In these cases women usually develop placenta praevia or accreta, which is often complicated by severe post partum haemorrhage and peri-partum hysterectomy. ${ }^{5}$ Various methods directed at reducing the bleeding from the implantation sites have been used in conjunction with dilatation and curettage (D\&C). These include insertion of Foley catheter into the cervix, intracervical vasopressin injection, cervical Shirodkar circlage, transvaginal ligation of cervical branches of uterine arteries or angiographic uterine artery embolisation. The use of any of these methods in adjunction with $\mathrm{D} \& \mathrm{C}$ reduces risk of hysterectomy from $40 \%$ to $<5 \%$. $^{6}$

1. Assistant Professor, Department of Obstetrics and Gynaecology, Enam Medical College \& Hospital, Savar, Dhaka

2. Professor, Department of Obstetrics and Gynaecology, Enam Medical College \& Hospital, Savar, Dhaka

3. Associate Professor, Department of Obstetrics and Gynaecology, Enam Medical College \& Hospital, Savar, Dhaka

Correspondence Sumia Bari, Email: sumia-bari@hotmail.com 


\section{Case-1}

A $3^{\text {rd }}$ gravida 26 -year-old female presented with per vaginal bleeding. She had a history of one caesarean section at full term and one previous spontaneous abortion. She had amenorrhoea for 3 months and had features of pregnancy. As this was an unwanted pregnancy, she induced abortion by taking tablet misoprostol at home. Subsequently she developed lower abdominal pain with per vaginal bleeding. On examination, she was conscious with pulse 110 beats/min, BP $90 / 50 \mathrm{~mm}$ of $\mathrm{Hg}$, respiratory rate 24 breaths/min and temperature was $98.4^{0} \mathrm{~F}$. She was severely anaemic, non-icteric and mildly dehydrated. Her cardio-respiratory examination revealed no abnormalities. There was mild tenderness in abdomen and height of the uterus was palpable just above the pubic symphysis. On inspection (per speculum) blood was coming out from the uterus, amount was more than average and cervix was broad (ballooning of the cervix). Bimanual examination of uterus revealed that size of the uterus was of 14 weeks; cervix was enlarged, soft and tender. The provisional diagnosis was incomplete abortion. Patient was treated with intravenous (IV) fluids, plasmasol, IV antibiotics, analgesics and antiulcerant. Her $\mathrm{Hb} \%$ was $6.8 \mathrm{gm} / \mathrm{dL}$. Two units of fresh blood were transfused. After correction of anaemia, evacuation and curettage $(\mathrm{E} \& \mathrm{C})$ was planned under general anaesthesia (Ketamin). With all aseptic precautions, small size $(4 \mathrm{~mm})$ canula was introduced but it failed to reach up to uterine cavity. So the canula was withdrawn and there was huge amount of blood coming out from uterus. To control the bleeding descending branches of cervical artery in both sides were ligated. However, bleeding was not controlled. So, immediate decision for laparotomy was taken. After opening the abdomen there was no perforation over the uterine wall and previous scar on the uterus was intact. Bladder was adherent to the lower segment of uterus; bladder was gently separated and lower uterine segment was reached. Then incision was given over the previous scar where retained product of conception was adhering. Upper uterine cavity was empty. Then product of conception was removed by sponge holding forceps. There was small amount of product of conception found tightly adherent to the cavity which was removed by digital separation. Then uterus was closed in layers after giving some mattress suture. Oozing point was secured by cauterisation and spongiostat. A drain tube was kept in situ. Product of conception was sent for histopathology. So, the case was confirmed as cervical pregnancy. Inj methotrexate $50 \mathrm{mg}$ IM stat was given systematically according to the advice of oncologist after the operative procedure. Her bleeding stopped completely and she was discharged in good health status on $4^{\text {th }}$ postoperative day.

\section{Case-2}

A $2^{\text {nd }}$ gravida 24 -year-old female presented with amenorrhoea for 8 weeks and mild lower abdominal pain followed by per vaginal bleeding which was blackish in colour and slight in amount. She had a history of one caesarean section. On examination, she was conscious, her pulse was 80 beats/min, BP 110/70 $\mathrm{mm}$ of $\mathrm{Hg}$, respiratory rate 20 breaths/min and temperature was $98.4^{0} \mathrm{~F}$. She was mildly anaemic and non-icteric. There was mild tenderness on palpation of the abdomen. Height of the uterus could not be palpated. Vaginal examination was not done as the provisional diagnosis was threatened abortion. Ultrasonography of lower abdomen revealed a gestational sac located over the scar line of previous caesarean wound suggestive of features of missed abortion. So, decision for evacuation of gestational content by medical method was taken. As per advice of oncologist IV methrotrexate was given according to body weight of the patient. She got methotrexate and folinic acid in alternate days for eight days. Injection methotrexate was administered on days $1,3,5$ and 7 and injection folinic acid was given on days 2, 4, 6 and 8. Patient had per vaginal bleeding with passage of clot and product of conception. Tablet misoprostol 200 microgram three times daily was added to accelerate uterine contraction and expulsion of product of conception. Patient was discharged after completion of the course of methotrexate and folinic acid regime and advised to come for follow-up routinely. Serum beta hCG was checked after 7 days and it was 115 IU/L, there was mild per vaginal bleeding and no sign of infection. After 14 days beta hCG came down to baseline (5 IU/L). USG of lower abdomen showed no retained product of conception.

\section{Discussion}

In case-1, the foetus was implanted below the previous caesarean section scar. The uterus was empty and the 
gestational sac showed evidence of foetal heart rate at 6-7 weeks in two different ultrasounds. Cervix was distended on ultrasound examination. Colour Doppler also confirmed blood flow around the gestational sac. Unlike true cervical pregnancy, cervical abortion is suggested by the body of the uterus being larger than in the nongravid state owing to the recent loss of the intrauterine sac. Serial ultrasound examinations performed over a few days should distinguish the cervical abortion by the transience of the sac if the diagnosis is in doubt. ${ }^{7,8}$ Two previous ultrasounds in our patient showed evidence of foetal heart activity and placement of the gestational sac in the cervix. Patients with cervical pregnancy classically present with painless first trimester vaginal bleeding although several case reports (including this one) describe patients with cramping pain. Treatment choices may be divided into different categories: balloon tamponade of implantation site after evacuation, reduction of blood supply by uterine artery embolisation, intracervical vasopressin injection, excision of trophoblastic tissue, intra-amniotic foeticide and systemic chemotherapy. ${ }^{7}$ In most reported cases of cervical pregnancy, treatments from more than one category are used..$^{8}$ Our patient presented with active bleeding and history of induced abortion. So during the process of evacuation of product of conception, there was torrential bleeding due to separation of immature trophoblastic tissue from the implantation site. Moreover, as there was chance of severe morbidity following emergency hysterectomy, in this case this was prevented by hysterotomy and removal of product of conception very gently.

In case-2, gestational content was removed by medical method followed by administration of IV methotrexate and folinic acid. Treatment with methotrexate chemotherapy of patients with either viable or nonviable cervical pregnancies at $<12$ weeks gestation carries a high success rate for preservation of the uterus. ${ }^{9}$ Methotrexate (MTX) is an antagonist to folic acid which is reduced to tetrahydrofolate by the enzyme dihydrofolate reductase (DHFR), a step in the synthesis of DNA and RNA precursor. MTX inhibits DHFR, causing depletion of cofactors required for DNA and RNA synthesis. As a consequence treatment with MTX is highly toxic to rapidly replicating tissues and achieves result comparable to surgery for the treatment of selected ectopic pregnancy. The dosage of $1 \mathrm{mg} / \mathrm{kg}$ locally was determined by a previously reported pharmacokinetics study. ${ }^{10}$ In a study, approximately $35 \%$ of women with ectopic pregnancy are eligible for medical treatment. The overall success rate of medical treatment in properly selected cases is nearly $90 \% .^{11-14}$

Increasing trend of caesarean sections and using other invasive methods such as intrauterine device and in vitro fertilisation seem to contribute to a higher prevalence of cervical pregnancies these days. Primary care providers who are involved in obstetric care should include this entity in the differential diagnoses in case of presentation with bleeding and cramping early in pregnancy as early diagnosis and consultation for interventional management is necessary in preserving patient's fertility without significant complications. The modern gynaecologist needs to be aware of this condition since intervention like dilatation and curettage performed for incomplete abortion can be catastrophic if diagnosis of cervical ectopics is not considered.

\section{References}

1. Vial Y, Petignat P, Hohtfeld P. Pregnancy in a caesarean scar. Ultrasound Obstet Gynecol 2000; 16: 592-593.

2. Marcovici I, Rosenzweig BA, Brill AI, Khan M, Scommegna A. Cervical pregnancy: case reports and a current literature review. Obstetrical and Gynecological Survey 1994; 49(1): 49-55.

3. Ushakov FB, Elchalal U, Aceman PJ, Schenker JG. Cervical pregnancy: past and future. Obstetrical and Gynecological Survey 1997; 52(1): 45-59.

4. Ushakov FB, Elchalal U, Aceman PJ, Schenker JG. Cervical pregnancy: past and future. Obstet Gynaecol Surv 1996; 52: 45-57.

5. Herman A, Weinraub Z, Avrech O, Maymon R, Ron-El R, Bukovsky Y. Follow-up and outcome of isthmic pregnancy located in a previous caesarean scar. Br J Obstel Gynecol 1995; 8: 373-380.

6. Jurkovic D, Hacket E, Campbell S. Diagnosis and treatment of early cervical pregnancy: a review and report of two cases treated conservatively. Ultrasound Obstet Gynecol 1996; 8: $373-380$.

7. Vas W, Suresh PL, Tang-Barton P, Salimi Z, Carlin B. UItrasonographic differentiation of cervical abortion from cervical pregnancy. Journal of Clinical Ultrasound 1984; 12(9): 553-557.

8. Kung FT, Chang SY. Efficacy of methotrexate treatment in viable and nonviable cervical pregnancies. American Journal of Obstetrics and Gynecology 1999; 181(6): 1438-1444. 
9. Hung TH, Shau WY, Hsieh TT, Hsu JJ, Soong YK, Jeng CJ. Prognostic factors for an unsatisfactory primary methotrexate treatment of cervical pregnancy: a quantitative review. Hum Reprod 1998; 13(9): 2636-2642.

10. Fernandez H, Bourget P, Ville Y, Lelaidier C, Frydman R. Treatment of unruptured tubal pregnancy with methotrexate: pharmacokinetic analysis of local versus intramuscular administration. Fertil Steril 1994; 62: 943-947.

11. Van Den Eden SK, Shan J, Bruce C, Glasser M. Ectopic pregnancy rate and treatment utilization in a large managed care organization. Obstet Gynecol 2005; 105: 1052.
12. Barnhart KT, Gosman G, Ashby R, Sammel M. The medical management of ectopic pregnancy: a meta-analysis comparing "single dose "and "multi dose" regimens. Obstet Gynaecol 2003; 4: 778-784.

13. Alleyassin A, Khademi A, Aghahosseini M, Safdarian L, Badenoosh B, Hamed EA. Comparison of success rates in the medical management of ectopic pregnancy with single dose and multi-dose administration of methotrexate: a prospective randomized clinical trial. Fertil Steril 2006; 6: 1661-1666.

14. Kamm BL. Emergency ultrasound for ectopic pregnancy. Radiol Technol 1998; 6: 519-531. 